\title{
Recommending Learning Activities as Strategy for enabling Self-regulated Learning
}

\author{
Pablo Lachmann \\ Knowledge Media Institute \\ University of Koblenz-Landau \\ Koblenz, Germany \\ e-mail: pablo.lachmann@uni-koblenz.de
}

\author{
Andreas Kiefel \\ Knowledge Media Institute \\ University of Koblenz-Landau \\ Koblenz, Germany \\ e-mail: andreas.kiefel@uni-koblenz.de
}

\begin{abstract}
This paper proposes the usage of a learning activity based recommendation approach for fostering self-regulated learning in a personal learning environment. For this purpose two widgets are developed and evaluated, which allow learners to compile an individual learning plan from recommendations of learning activities that match a given task.
\end{abstract}

Keywords-Self-regulated learning; learning strategy; recommendations; personal learning environment

\section{INTRODUCTION}

For the personalization of learning environments learners have to set up their learning space in a meaningful way for their learning task. In self-regulated learning (SRL) situations where learners take responsibility for the learning process and outcome the competent application of learning strategies is considered helpful for learners and to lead to better learning performance [1][2]. By anticipating the learning process learners can decide which tools and resources they want to use and how to assemble their learning environment. The idea of a "Learning Activity Recommender" widget is to support this anticipation by creating a learning plan. Learners select and modify activities from various recommended strategies and techniques matching their individual task or learning situation. While processing a task learners can modify their plans according to their evolving needs.

\section{SUPPORTING SELF-REGULATED LEARNING}

In ROLE the Psycho-pedagogical Integration Model (PPIM) is used to describe SRL processes [3]. The four phases of the PPIM ${ }^{1}$ are characterized by assigned key activities, which are realized by applying learning strategies and learning techniques [3][4]. E.g. for the key activity "goal setting" a learner may choose the SMART strategy.

\section{A. Acquisition of learning strategies}

From a practical point of view learning strategies can be understood as an explicit learning aids which are covering

\footnotetext{
${ }^{1}$ Four phases of the PPIM: 1) Learner profile information is defined or revised, 2) Learner finds and selects learning resources, 3) Learner works on selected learning resources, and 4) Learner reflects and reacts on strategies, achievements and usefulness [3]
}

essential declarative, procedural, and conditional knowledge [1] for selecting useful and efficient learning activities for successful learning which learners can acquire, rehearse, and apply in various learning situations.

The teaching of learning strategies is subject to intensive research [1][5], resulting in various approaches to teach SRL. For internalization of learning strategies embedding metacognitive and cognitive instruction and rehearsing in a course or task is recommended [1][6]. Learners normally use own strategies, however "as a result of diverse and changing intrapersonal, interpersonal, and contextual conditions, selfregulated individuals must continuously adjust their (...) choice of strategies" [7].

For the rehearsal of learning strategies in an authentic utilization context, a "Learning Activity Recommender" widget, that recommends learning strategies to help learners mastering a task at hand, is designed and developed within the ROLE project.

At the moment the focus of strategy learning support is on cognitive activities. Learners create a presentation, do mindmapping, brainstorming, or outlining. In the PPIM-model these kinds of activities match Phase 3, but due to its design the "Learning Activity Recommender" also can support metacognitive strategies, e.g. for goal setting, time management, or self-evaluation. In order to be supported a strategy or technique needs to be based on a set or sequence of learning activities. Non-process parts, like hints, cues or references can additionally be given in a text field. The possibility to support volitional strategies [8][7] and motivational and affective strategies has still to be elaborated on.

\section{B. Learning about self-regulated learning}

Explicit knowledge is important when unexpected events or errors occur while processing a learning task or a problem [9]. The "Learning Activity Recommender" provides declarative, procedural and conditional knowledge about strategies and techniques by displaying the steps (concrete activities) of a strategy and a description. This way it presents the needed knowledge at a relevant point of time in the decision process to the learner and therefore serves as integrated part for SRL competence development. 
The recommender widget should help learners to see more appropriate and more efficient alternatives to the strategies they have developed over time. "As a skill develops, the effectiveness of an initial acquisition strategy often declines to the point where another strategy becomes necessary" [7]. It also provides information like possible next learning steps and information about a proposed learning strategy. By means of the information learners get from the recommender, they should be able to make a decision on how to proceed or at least be inspired to try out some alternatives.

\section{Personalization by adaption of learning strategies}

The "Learning Activity Recommender" guides the learner through the learning process by recommending learning activities related to the PPIM phases. Learners with higher SRL competency are able to skip recommendations, e.g. an instruction on how to carry out mind mapping. The learner is guided by means of a step-by-step approach of how to cope with a problem. In contrast to a direct instruction the learner can decline to accept learning activities and can choose between alternatives and will not be penalized for varying his learning steps from what is suggested.

\section{LEARNING ACTIVITY RECOMMENDER}

Currently, two widgets are implemented, which are needed for using activity recommendations: The "Learning Activity Recommender" widget and the "Learning Plan" widget ("To-Learn List") (Figure 1). The "Learning Activity Recommender" widget shows the learners the current task, matching learning strategies, a list of concrete learning steps of a selected learning strategy and related information.

\begin{tabular}{|c|c|c|}
\hline To-Learn list & \multicolumn{2}{|r|}{ Activity Recommender } \\
\hline Quick add: & \multirow[b]{2}{*}{ Task: } & \multirow[b]{2}{*}{$\begin{array}{l}\text { Select a strategy to create a } \\
\text { presentation. }\end{array}$} \\
\hline Level 1: $\quad$ Order: Manual $:$ & & \\
\hline \multirow{10}{*}{$\begin{array}{l}\text { Write down why are you making this presenta... } \\
\text { Write down who are you making this presenta... } \\
\text { Write down where are you making this prese... } \\
\text { Write down when are you making this present... } \\
\text { + Find out what is the content of your present... }\end{array}$} & \multicolumn{2}{|c|}{ Select Learning Strategy: } \\
\hline & \multicolumn{2}{|c|}{ Wh-questions strategy for creating presentations } \\
\hline & \multicolumn{2}{|c|}{$\square$ Activities: } \\
\hline & \multicolumn{2}{|c|}{$\begin{array}{l}\square \text { Write down why are you making this } \\
\text { presentation }\end{array}$} \\
\hline & \multicolumn{2}{|c|}{$\begin{array}{l}\text { Write down who are you making this } \\
\text { presentation to }\end{array}$} \\
\hline & \multicolumn{2}{|c|}{$\begin{array}{l}\square \text { Write down where are you making this } \\
\text { presentation. }\end{array}$} \\
\hline & \multicolumn{2}{|c|}{$\begin{array}{l}\text { Write down when are you making this } \\
\text { presentation and how long will it be. }\end{array}$} \\
\hline & \multicolumn{2}{|c|}{$\begin{array}{l}\text { + Find out what is the content of your } \\
\text { presentation. }\end{array}$} \\
\hline & & $\begin{array}{l}\text { + Think about how you want to make this } \\
\text { presentation. }\end{array}$ \\
\hline & \multicolumn{2}{|c|}{ Select } \\
\hline
\end{tabular}

Figure 1. „Learning Plan“ widget and „Learning Activity Recommender“ widget running in the ROLE SDK test environment

When learners decide to use a learning strategy, the "Learning Activity Recommender" widget sends learning activities to the "Learning Plan" widget, which empowers learners to compile and modify an individual learning plan. They also can add own activities, e.g. reminding their selves to take a coffee break after a brainstorming session.

As a first step these widgets have been evaluated by participatory observation and an additional online survey with four participants of a German learning course at the "Zentrum für Fernstudien und universitäre Weiterbildung" covering the main categories of the Technology Acceptance Model 3 (TAM3) [10], namely perceived usefulness and perceived ease of use. Other evaluated categories are objective usability and attitude acceptance.

The learners had a face-to-face introduction in the handling of the evaluation setup. Their task was to give a presentation about a free topic. After their presentation ten days later, they were asked to fill out an online survey. While especially the idea of recommending strategies got some positive feedback, the current state of the handling the widgets were criticized. More detailed results will be presented at the workshop. Other formative evaluation of the widgets is planned and will be carried out in the first half of the year.

\section{ANTICIPATED OUTCOMES}

From the workshop participants we'd like to get some input especially on the following topics: 1) Integration of the "Learning Activity Recommender" in the ROLE infrastructure, 2) Additional recommender functionalities (e.g. visualization of the learning plan for navigation), 3) Complementing widgets, and 4) Reusing existing available databases of learning methods as a learning strategy resource.

\section{REFERENCES}

[1] C. E. Weinstein, J. Husman, and D. R. Dierking, "Self-regulation interventions with a focus on learning strategies," in Handbook of Selfregulation, 2nd ed., M. Boekaerts, P. R. Pintrich, and M. Zeidner, Eds. Burlington, San Diego, London: Elsevier Academic Press, 2005, pp. 727 747.

[2] U. Schiefele, "Prüfungsnahe Erfassung von Lernstrategien und deren Vorhersagewert für nachfolgende Lernleistungen," in Lernstrategien und Metakognition. Implikationen für Forschung und Praxis, C. Artelt and B. Moschner, Eds. Münster: Waxmann, 2005.

[3] A. Nussbaumer and K. Fruhmann, Eds., "Common psycho-pedagogical framework. Deliverable for the European Commission." 2011. http://www.role-project.eu/?page_id=494.

[4] A. Kiefel, S. Govaerts, and M. Palmér, Eds., "The ROLE Theoretical Framework." 2011. http://www.role-project.eu/?page_id=1108.

[5] M. Berthold, P. Lachmann, A. Nussbaumer, S. Pachtchenko, A. Kiefel, and D. Albert, "Identifying Requirements for a Psycho-Pedagogical Mash-up Design for Personalising the Learning Environment," in Advances in User Modeling perspectives - selected papers from UMAP 2011 workshops, Heidelberg: Springer.

[6] L. Corno, "Volitional aspects of self-regulated learning," in Self-regulated learning and academic achievement. Theoretical perspectives, 2nd ed., B. J. Zimmermann and D. H. Schunk, Eds. Mahwah, New Jersey, London: Lawrence Erlbaum Associates, 2001, pp. 191-225.

[7] B. J. Zimmermann, "Attaining self-regulation. A social cognitive perspective," in Handbook of Self-regulation, M. Boekaerts, P. R. Pintrich, and M. Zeidner, Eds. Burlington, San Diego, London: Elsevier Academic Press, 2005, pp. 13-39.

[8] R. Vollmeyer, "Ansatzpunkt für die Beeinflussung von Lernmotivation," in Handbuch Lernstrategien, H. Mandl and H. F. Friedrich, Eds. Göttingen, Bern, Wien, Toronto, Seattle, Oxford, Prag: Hogrefe, 2006, pp. 223-231.

[9] M. V. J. Veenman, "The assesment of metacognitive skills: What can be learned from multi-method designs?," in Lernstrategien und Metakognition. Implikationen für Forschung und Praxis, C. Artelt and B. Moschner, Eds. Münster: Waxmann, 2005.

[10] V. Venkatesh and H. Bala, "TAM 3: Advancing the Technology Acceptance Model with a Focus on Interventions." http://www.vvenkatesh.com/organizations/Theoretical Models.asp. 